LESLIE (Donald Daniel), Jews and Judaism in Traditional China. A Comprehensive Bibliography

Sankt Augustin (All.), Monumenta Serica Institut, 1998, 291 p. (bibliogr., index, illustr.) (coll. « Monumenta Serica Monograph Series » XLIV)

Françoise Aubin

\title{
CpenEdition
}

Journals

Édition électronique

URL : http://journals.openedition.org/assr/20671

DOI : $10.4000 /$ assr.20671

ISSN : $1777-5825$

Éditeur

Éditions de l'EHESS

Édition imprimée

Date de publication : 1 juillet 2000

Pagination : 123-124

ISBN : 2-222-96691-4

ISSN : 0335-5985

Référence électronique

Françoise Aubin, «LESLIE (Donald Daniel), Jews and Judaism in Traditional China. A Comprehensive Bibliography », Archives de sciences sociales des religions [En ligne], 110 | avril-juin 2000, document 110-77, mis en ligne le 19 août 2009, consulté le 21 septembre 2020. URL : http:// journals.openedition.org/assr/20671; DOI : https://doi.org/10.4000/assr.20671

Ce document a été généré automatiquement le 21 septembre 2020

(c) Archives de sciences sociales des religions 


\section{LESLIE (Donald Daniel), Jews and Judaism in Traditional China. A Comprehensive Bibliography}

Sankt Augustin (All.), Monumenta Serica Institut, 1998, 291 p. (bibliogr., index, illustr.) (coll. « Monumenta Serica Monograph Series » XLIV)

\section{Françoise Aubin}

\section{RÉFÉRENCE}

LESLIE (Donald Daniel), Jews and Judaism in Traditional China. A Comprehensive

Bibliography, Sankt Augustin (All.), Monumenta Serica Institut, 1998, 291 p. (bibliogr., index, illustr.) (coll. « Monumenta Serica Monograph Series » XLIV)

D.D.L. (de Canberra, Australie) est, sans contredit, le meilleur spécialiste mondial de deux disciplines rares et difficiles, l'islam littéraire chinois des XVII ${ }^{\mathrm{e}}$-XVIII ${ }^{\mathrm{e}}$ siècles et le judaïsme chinois. Ses lectures en toutes langues sont immenses; et, il y a bien longtemps déjà qu'il a fait profiter les islamisants d'un ouvrage de référence biobibliographique, resté irremplaçable, sur le premier de ces champs de recherche (Islamic Literature in Chinese, Canberra College of Advanced Education, 1981). La présente bibliographie, qui a bénéficié de l'assistance éditoriale impeccable du P.R. Malek, le directeur de Monumenta Serica, est d'une ampleur et d'une érudition à couper le souffle (la liste de ses propres travaux sur le judaïsme chinois, pp. 149-151 et 109, se monte à une quarantaine de titres, dont quatre livres, seul ou en collaboration, et deux livres sur l'islam chinois faisant une part à l'hébraïsme). L'ouvrage est si bien conçu que même le non-spécialiste peut glaner des informations d'intérêt, ainsi dans le bref récapitulatif de la présence juive en Chine (pp. 15ss.) : au moins dès le IX $\mathrm{IX}^{\mathrm{e}}$ siècle, sinon plus tôt, très marquée à K'ai-feng à partir du XII ${ }^{\mathrm{e}}$ siècle, florissante jusqu'au XVIII ${ }^{\mathrm{e}}$ siècle, virtuellement éteinte $\mathrm{au} \mathrm{XX}^{\mathrm{e}}$ siècle par assimilation avec la culture chinoise, et cependant redécouverte par le régime populaire dans les années quatre-vingt. C'est 
cette communauté qui forme le noyau principal de la présente documentation, à l'exclusion des communautés juives européennes, russes principalement, réfugiées en Chine devant la montée du nazisme ou du stalinisme.

Les listes successives portent sur les sources internes de la communauté de K’ai-feng (pp. 25-38); les anciennes sources chinoises relatives soit à la Judée, à la Syrie, à Jérusalem ou aux récits bibliques, soit à cette communauté de K’ai-feng (pp. 39-45); les liens éventuels ou franchement imaginaires avec les juifs d'origine ou de la diaspora (pp. 46-48); les informations à tirer de voyageurs ou géographes arabes et persans du $\mathrm{IX}^{\mathrm{e}}$ au $\mathrm{XV}^{\mathrm{e}}$ siècle et occidentaux du XIII ${ }^{\mathrm{e}}$ au XVIII ${ }^{\mathrm{e}}$ siècle (pp. 49-59), de récits de voyageurs occidentaux aux $\mathrm{XIX}^{\mathrm{e}}$ et $\mathrm{XX}^{\mathrm{e}}$ siècles (pp. 59-65). Suit une bibliographie des études occidentales, par ordre alphabétique des auteurs et chronologiquement sous chaque nom (pp. 86-205), ainsi que des récapitulatifs et des références croisées des auteurs essentiels (pp. 177-182), des périodiques (pp. 206-227), des auteurs ayant publié en d'autres langues que l'anglais, le français et l'allemand (pp. 228-230); enfin une belle bibliographie des études en chinois, anciennes ou récentes (avec caractères chinois et traduction des titres), menée, sauf erreur de notre part, jusqu'en 1993 et touchant aux publications de la Chine continentale autant qu'à celles de Taïwan (pp. 232-249); et des travaux japonais, du XIX ${ }^{e}$ siècle à 1990 (pp. 250-252). Le copieux index général est doté, lui aussi, de caractères chinois (pp. 255-291). Les espaces blancs sont occupés par des reproductions de pages de garde des publications les plus connues sur le sujet.

D.D.L. a lu et utilisé la plus grande partie des titres qu'il cite, aussi est-ce en connaissance de cause qu'il en caractérise le contenu et en apprécie la valeur par l'attribution d'un à quatre astérisques aux plus méritants. Il a même poussé la conscience professionnelle jusqu'à relever les titres dont il avait attendu, en vain, des lumières sur le sujet, afin d'éviter à ses utilisateurs des recherches inutiles. Il suffit de feuilleter le recueil pour mesurer l'ampleur du domaine - peut-on dire insoupçonnée ? - et comprendre la place qu'occupent, dans notre connaissance de la communauté de K'ai-feng et de sa synagogue, les observations des missionnaires, des jésuites aux XVII ${ }^{e}-\mathrm{XVIII}{ }^{\mathrm{e}}$ siècles, au premier chef desquels Jean-Paul Gozani en 1704 et 1712 (p. 56) et Jean Domenge en 1717-1725 (p. 57), puis, dans les deux siècles suivants, des protestants (ainsi les délégués chinois de l'évêque Smith en 1850-1851, p. 60). L'hypothèse que l'évêque protestant $\mathrm{Wm}$. C. White avait une arrière-pensée de prosélytisme lorsqu'il tentait, en 1919, de redonner vie à la communauté de K'ai-feng, est écartée avec élégance par D.D.L., au nom de la reconnaissance que nous devons aux protestants, et à celui-là en particulier, pour leurs notations sur la communauté en péril (p.63). On le voit, nonobstant sa technicité, cette bibliographie exemplaire a de quoi nourrir des questions et fournir des réponses aux curieux. 